\title{
Light as stress factor to plant roots - case of root halotropism
}

\author{
Ken Yokawa ${ }^{1,2}$, Rossella Fasano ${ }^{3}$, Tomoko Kagenishi ${ }^{1}$ and František Baluška ${ }^{1}$ * \\ 'Department of Plant Cell Biology, Institute of Cellular and Molecular Botany, University of Bonn, Bonn, Germany \\ 2 Department of Biological Sciences, Tokyo Metropolitan University, Tokyo, Japan \\ ${ }^{3}$ Department of Pharmacy, University of Salerno, Fisciano, Italy
}

Edited by:

Vadim Volkov, London Metropolitan

University, UK

Reviewed by:

Francois Bouteau, Université Paris

Diderot, France

Zheng-Hui He, San Francisco State

University, USA

*Correspondence:

František Baluška, Department of Plant Cell Biology, Institute of Cellular and Molecular Botany, University of Bonn, Kirschallee 1, 53115 Bonn,

Germany

e-mail:baluska@uni-bonn.de
Despite growing underground, largely in darkness, roots emerge to be very sensitive to light. Recently, several important papers have been published which reveal that plant roots not only express all known light receptors but also that their growth, physiology and adaptive stress responses are light-sensitive. In Arabidopsis, illumination of roots speedsup root growth via reactive oxygen species-mediated and F-actin dependent process. On the other hand, keeping Arabidopsis roots in darkness alters F-actin distribution, polar localization of PIN proteins as well as polar transport of auxin. Several signaling components activated by phytohormones are overlapping with light-related signaling cascade. We demonstrated that the sensitivity of roots to salinity is altered in the light-grown Arabidopsis roots. Particularly, light-exposed roots are less effective in their salt-avoidance behavior known as root halotropism. Here we discuss these new aspects of light-mediated root behavior from cellular, physiological and evolutionary perspectives.

\section{LIGHT AS IMPORTANT ENVIRONMENTAL FACTOR FOR ROOTS}

In nature, sessile plants have to respond to diurnal change in the light environment. One of main roles of light in plant's life is to provide energy for photosynthesis and for the regulation of plant development at different stages such as seed germination, vegetative growth, tropisms and flowering. It is known that plant photoreceptors and related light-sensitive signaling molecules participate in the regulation of physiological conditions and morphological plasticity in response to the light environment. Darwin (1879) has discovered negative phototropism of plant roots. One year later, Francis Darwin and his father, Charles Darwin, published the book, "The Power of Movements in Plants." They described both root and shoot tropisms. In addition, they also proposed that some form of long-distance signaling connect the sensory organ apices with the actively growing basal parts (Darwin, 1879, 1880). Since then, dedicated research work in plant physiology has discovered the long-distance signaling molecule, auxin, resulting in insights into plant photoreception. This directional growth response to incoming light is called phototropism. Positive phototropism, observed in shoots, is growth toward a light source; whereas negative phototropism, seen in roots, is bending away from the light source. We demonstrated that short (10 s), but strong (the photon flux was $82 \mu \mathrm{mol} \mathrm{m} \mathrm{m}^{-2} \mathrm{~s}^{-1}$ ), blue light illumination of Arabidopsis roots induces the immediate generation of reactive oxygen species (ROS) in root apex region, resulting in rapid increase of the root growth rate (Yokawa et al., 2011, 2013). This active response of light-stimulated root growth is termed escape tropism (Xu et al., 2013; Yokawa et al., 2013; for maize roots see Burbach etal., 2012). This tropism would allow Arabidopsis roots to escape from unfavorable light conditions if growing outside of our laboratories in the nature.

\section{PHOTORECEPTORS IN ROOTS}

It has been shown that Arabidopsis plant expresses 14 photoreceptors, most of which are also present in roots (Briggs and Lin, 2012; Jeong and Choi, 2013; Briggs, 2014). Roots grow in the dark soil to anchor the plant and to absorb mineral nutrients and water. It has been reported that light can penetrate less than several millimeters due to the rather high absorbance of soil (Woolley and Stoller, 1978). Nevertheless, small cracks or mechanical impacts can often happen which allows light to penetrate deeper. For instance, roots may be exposed to light due to sudden temperature changes, earthquake, heavy rain, wind, and so on. In addition, it is very important for emerging radicle to increase the root growth rate shortly after seed germination on the ground. It was necessary to evolve the ability of roots to respond to environmental light when the first flowering plants with modern root system emerged in land plant evolution. In the next section, intriguing interplays between phytohormones and light-related signaling pathways will be discussed.

\section{FROM ACTIN CYTOSKELETON, VIA PIN2 RECYCLING, TO SALT AVOIDANCE TROPISMS OF ROOTS}

At the cellular level, it was reported that PIN2 proteins (PINFORMED 2; auxin efflux carrier) in root apices respond to the light environment (Laxmi et al., 2008). Wan et al. (2012) demonstrated that the basipetal (shootward) PIN2-based polar auxin transport is subject to blue light control, which regulates the negative phototropism of Arabidopsis roots (Wan et al., 2012). Moreover, Dyachok et al. (2011) reported that light-activated COP1, E3 ubiquitin ligase, promotes actin polymerization and F-actin bundling, through regulation of the downstream ARP2/3-SCAR pathway in root cells. It results in increased root growth under the illuminated conditions (Dyachok et al., 2011). It was also reported 
that light controls bundling of F-actin in maize coleoptiles (Waller and Nick, 1997), changing sensitivity of cells to auxin, which is feeding back to control F-actin as well as cell growth (Nick et al., 2009). The interplays between F-actin and polar auxin transport mediated by endocytic vesicle recycling, especially in the transition zone of root apex, control root tropisms (Baluška et al., 1996, 2004, 2005, 2010; Baluška and Mancuso, 2013). Interestingly, precursor of endogenous auxin, indole-3-acetaldehyde (IAAld), is produced non-enzymatically in vitro by illumination of tryptophan in the presence of flavin which is abundant in living plant cells (Koshiba et al., 1993). Recently, we have proposed close links between the redox status and auxin (IAA) biosynthesis in plants (Yokawa et al., 2014). Taken together, it is obvious that roots are extraordinarily sensitive to light exposure due to their inherent evolutionary optimization for the underground life. Therefore, it is not surprising that illuminated roots of young Arabidopsis seedlings enhance their growth with the concomitant phototropism.

A few yeas ago, salt-stressed roots of Arabidopsis have been shown to alter root growth direction in order to avoid high salt areas via so-called salt avoidance tropism (Li and Zhang, 2008; Sun et al., 2008). This active root tropism requires ion gradient sensing pathway which would then control the PIN2 abundance, recycling and degradation (Li and Zhang, 2008; Sun et al., 2008). This unique Arabidopsis root behavior was linked to phospholipase D Zeta2 (PLD $\zeta 2$ ) activity which stimulates clathrin-mediated endocytosis of PIN2, and this tropism was also termed root halotropism (Galvan-Ampudia et al., 2013; Rosquete and KleineVehn, 2013; Pierik and Testerink, 2014). Interestingly, similarly, as in halotropism, PLD $\zeta 2$ is involved in root hydrotropism through the PIN2-mediated suppression of root gravitropism (Taniguchi et al., 2010). Moreover, PLD $\zeta 2$ is crucial for brefeldin A-sensitive endocytic recycling driving PIN2 recycling (Li and Xue, 2007) and polar auxin transport in the transition zone (Mancuso et al., 2007). Because PIN2 is crucial in this respect, as well as in adaptive responses of roots to light (Laxmi et al., 2008; Sassi et al., 2012; Wan et al., 2012), it is very important to test whether light condition affect the response of Arabidopsis roots to the salt stress.

\section{PLANT HORMONES ARE INTEGRATED WITH LIGHT SIGNALING PATHWAYS}

Karrikin molecule was isolated from the smoke of combusted plant materials and found to potently stimulate the germination of plant seeds (Flematti et al., 2004). This compound was identified as 3methyl-2H-furo[2,3-c] pyran-2-one, karrikin-1 or karrikinolide-1 $\left(\mathrm{KAR}_{1}\right)$ shown in Figure $\mathbf{1 A}-\mathrm{a}$, and another analogs of karrikins $\left(\mathrm{KAR}_{2}-\mathrm{KAR}_{6}\right)$ commonly possess butenolide structure. The Arabidopsis mutant kai2 lacking KAI2 genes insensitive to $\mathrm{KAR}_{1}$ triggered promotion of seed germination. KAI2 is thought to be a putative receptor of karrikins (Nelson et al., 2010; Waters et al., 2012). KAI2 is a member of $\alpha / \beta$-hydrolase family and is also known as HYPOSENSITIVE TO LIGHT (HTL). Role of KAI2/HTL in light responses (Figure 1B) of roots will be described in the next section.

Arabidopsis thaliana AtD14 (ortholog of DWARF14) is a paralog of KAI $2 / \mathrm{HTL}$, which belongs to $\alpha / \beta$-hydrolase family and plays a role in strigolactone perception (Waters et al., 2012).<smiles>Cc1c2ccocc-2oc1=O</smiles>

(a) $\mathrm{KAR}_{1}$

B

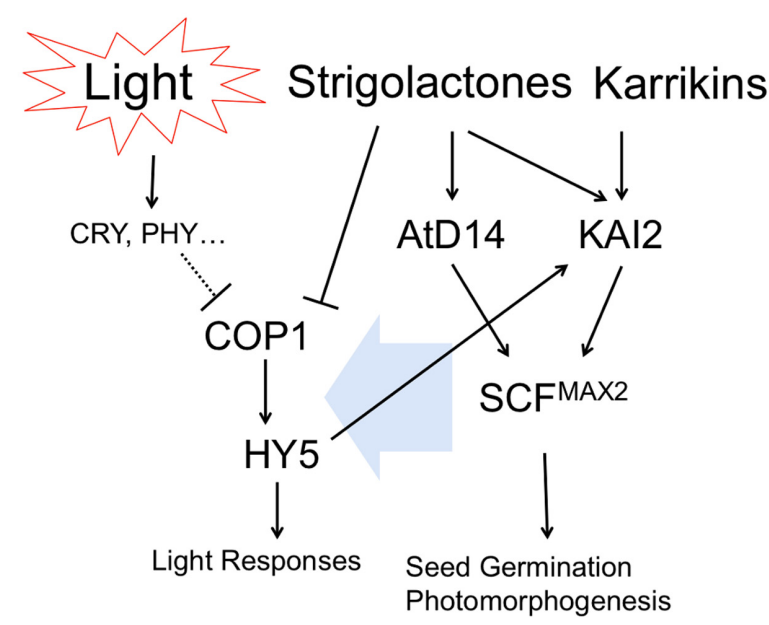

FIGURE 1 | Cross talk between butenolide plant hormones and light signaling pathways. (A) Chemical structures of (a) Karrikin1, $K A R_{1}$ and (b) Strigolactone analog, GR24. (B) Interaction of hormonal and light signaling pathways.

Strigolactones are synthesized from carotenoids and released into root exudates to promote germination of parasitic weeds (Yoneyama et al., 2007), as well as to stimulate hyphal branching in arbuscular mycorrhizal fungi (Akiyama et al., 2005). Strigolactones act also as a new class of plant hormone that inhibit the growth of axillary buds (Umehara etal., 2008) and alter root architecture (Koltai, 2011). Strigolactones are categorized as a sesquiterpenes lactone and have two moieties of butenolide (shown in Figure 1A-b as synthesized analog, GR24). As described above, karrikins have butenolide moieties as well. Therefore, because of the structural similarity of two molecules, karrikin receptor KAI2/HTL can respond to strigolactones. However, in contrast, the proposed strigolactone receptor AtD14 is insensitive to karrikins; indicating that the activity of KAI2/HTL as $\alpha / \beta$-hydrolase is more flexible to detect butenolide structure than AtD14, probably due to evolutionary issues (Waters et al., 2012).

It was reported that F-box protein, MORE AXILLARY BRANCHES2 (MAX2), is located in the downstream of both KAI2/HTL and AtD14 and thus necessary for plants to respond to karrikin and strigolactone (Nelson et al., 2010; Waters et al., 2012). MAX2 forms SCF E3 ubiquitin ligase complex (Skp1, Cullin1, F-box), which modulates further downstream transcriptions (Stirnberg et al., 2007; Shen et al., 2012). However, molecular functions of KAI2/HTL or AtD14-mediated SCFMAX2 regulation of plant morphogenesis are not known yet. Interestingly in this 
respect, $\max 2$ mutants are hyper-sensitive to drought and osmotic stress, including high $\mathrm{NaCl}$, mannitol, and glucose (Bu et al., 2014). Furthermore, strigolactones exert positive roles in plant adaptation to drought and salt stress (Ha et al., 2014). We will discuss these newly emerging aspects in the final section.

\section{LIGHT SIGNAL TRANSDUCTION VIA COP1 AND HY5 IS INTEGRATED WITH HORMONAL SIGNALING}

In principle, plants recognize light as specific wavelengths by specific photoreceptors. Activated (excited) photoreceptors convert the light information into physiological signaling in diverse manners. CONSTITUTIVE PHOTOMORPHOGENIC1(COP1), E3 ubiquitin ligase, participates in the light-perceiving signaling cascade via affecting ubiquitination of target proteins. Once the activity of COP1 is inhibited, the downstream bZIP transcription factor, ELONGATED HYPOCOTYL5 (HY5) is freed from ubiquitination by COP1 and starts specific gene transcriptions related to light responses (Figure 1B left). COP1 and HY5 control root growth, lateral root formation, root hair tip growth, as well as root touch-responses and gravitropism (Oyama et al., 1997; Ang et al., 1998; Cluis et al., 2004; Datta et al., 2006, 2007; Sibout et al., 2006). Importantly, SALT TOLERANCE HOMOLOG2 (STH2) is interacting partner of COP1 and HY5 which controls roots and their anthocyanin levels (Datta et al., 2007).

Interestingly, exposure of plants to strigolactone inhibits the COP1 activity, suggesting that strigolactones can mimick light perception in plants (Tsuchiya et al., 2010). They also demonstrated that $\max 2$ mutant of rice produces excess of strigolactones, resulting in the inhibition of COP1 and expression of light-responsive genes (Tsuchiya et al., 2010). In addition, it was reported that max2 mutant is hypersensitive to red, far-red and blue light (Shen et al., 2007). Auxin interaction with the signaling pathway of strigolactones via MAX2 was already reported (Hayward et al., 2009). Finally, the key transcription factor of light signaling HY5 requires strigolactones in order to stimulate Arabidopsis seed germination during thermoinhibiton (Toh et al., 2012). Light also induces auxin biosynthesis via photoexcitation of flavins (Koshiba et al., 1993; Yokawa et al., 2014).

Karrikin receptor KAI2 is also known as HTL. KAI2/HTL expression was strongly increased by blue, red and far-red light and HY5 binds to the promoter region of HTL, indicating the expression of KAI2/HTL is regulated in response to light environment (Sun and Ni, 2011). Furthermore, KAI2/HTL is located downstream of HY5 (Figure 1B) and induced by light treatment (Sun and Ni, 2011). Meanwhile, it was reported that the treatment of seeds with $\mathrm{KAR}_{1}$ (chemical structure is shown in Figure 1A-a) improved light responses in germination and early development of seedlings (Nelson et al., 2010). It implies that karrikins can affect the array of gene expression regarding light responses.

Plant roots exposed to salinity stress increase abscisic acid (ABA) and ABA-related gene expressions (Raghavendra et al., 2010). ABA and strigolactones are synthesized from carotenoids and the levels of these two plant hormones are affecting each other (López-Ráez et al., 2010). Salt stress increases strigolactone levels in roots which then promote arbuscular mycorrhizal symbiosis, resulting in changing $\mathrm{ABA}$ contents and alleviating stress response
(Aroca et al., 2013). Strigolactones, ABA and cytokinin signaling pathways are integrated to allow plants to cope with high salinity environment very effectively (Ha et al., 2014). Many players of the phytohormone signaling pathways are overlapping and integrating with light-response pathways.

Taken together, these findings suggest that hormonal and light signaling pathway utilizes same junction for plant morphogenesis as well as for adaptation to abiotic stresses. The signaling pathways proposed (Figure 1B) are highly integrated, interacting with each other and, obviously, they represent just a 'tip of the iceberg.' In the case of roots, we should consider light solely as information (not as source of energy) into our careful consideration for our understanding of plant photomorphogenesis. In the next session, we are discussing how the root sensitivity to salinity is altered via exposure of roots to light.

\section{UV LIGHT AND UVR8 IN DROUGHT AND SALINITY RESPONSES OF ROOTS}

It has been reported that the reduction of plant growth under water deficit is driven by the UV-B photoreceptor UV RESISTANCE LOCUS 8 (UVR8; Kliebenstein et al., 2002; Brown et al., 2005; Favory et al., 2009; Fasano et al., 2014). Fasano et al. (2014) previously shown that the UVR8 gene complements the osmosensitive yeast mutant $m p k 1 p p z 1$. The expression of UVR 8 was found upregulated in Arabidopsis plants grown under salt or osmotic stress conditions. Furthermore, the ectopic expression of UVR8 causes pleiotropic effects on plant growth, such as a general reduction of plant organ size, leaves with smaller cells, reduced root growth, and the accumulation of flavonoids. This suggests that the UV-B morphogenic responses are enhanced in the UVR8overexpressing plants grown under low levels of UV-B light. The growth defects of the UVR8-overexpressing plants are even more severe under osmotic and salt stress. In contrast, the inactivation of UVR8 expression does not affect shoot or root growth under standard or mild drought stress conditions. Thus, the hypersensitive response to osmotic stress of the $35 S U V R 8$ plants is strictly UVR8-dependent (Fasano et al., 2014).

There are extensive evidences that osmotic stress as well as UV-B light impacts are more prominent on shoots than on roots. Under mild osmotic stress, roots continue to grow (Bartels and Sunkar, 2005; Pardo, 2010; Werner et al., 2010). Moreover, enhanced root growth was observed in transgenic plants with a higher drought or salt-stress tolerance (Bartels and Sunkar, 2005). Whereas the impact of osmotic stress on root development is well known (recently reviewed in Liu et al., 2014), effects of UV-B on root growth are poorly understood. In general UV-B reduces primary root growth of Arabidopsis seedling (Kim et al., 1998; Tong et al., 2008). In the adult plant, increased allocation of biomass to roots has been reported to occur under UV-B stress (Bussell et al., 2012).

Development of a larger root system is considered as a droughtavoidance strategy that plants adopt to improve the uptake of water and nutrients when their availability in the soil is limited (Fukai and Cooper, 1995; Liao etal., 2001; Sharp etal., 2004; Pierik and Testerink, 2014). The UV-B photoreceptor UVR8 is expressed in roots of wild type plants (Rizzini et al., 2011; reviewed in Yokawa and Baluška, 2014). As shown in Figure 2, UVR8::GFP is 


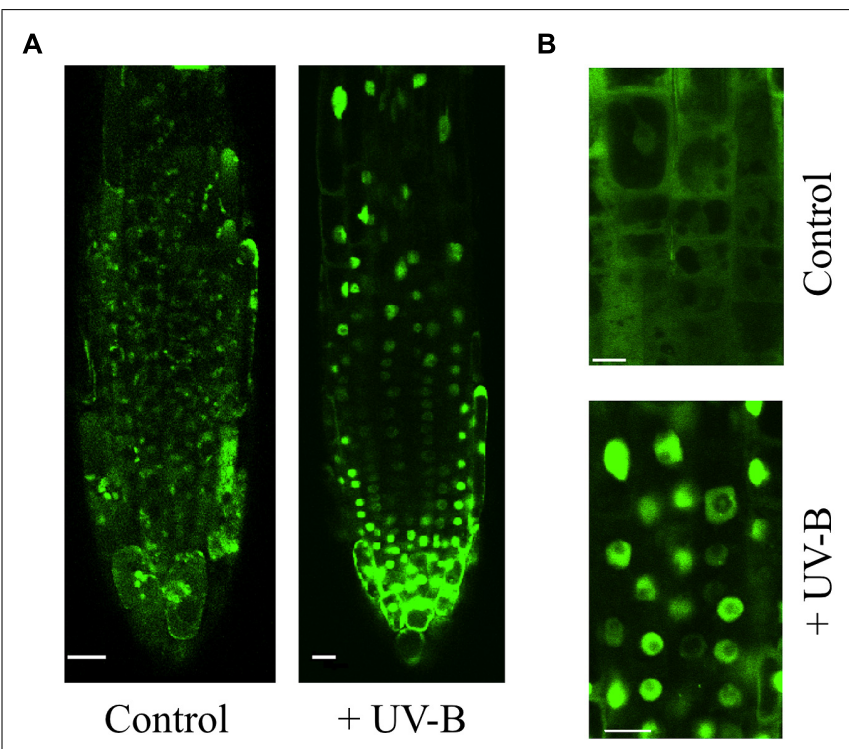

FIGURE 2 | Relocation of UVR8::GFP to nuclei in Arabidopsis root cells. (A) Root apex region. (B) Magnified view of cells in the transition zone. Bar indicates $10 \mu \mathrm{m}$. Arabidopsis roots were exposed to $1 \mathrm{~h}$ UV-B treatment $\left(3.9 \mu \mathrm{mol} \mathrm{m} \mathrm{m}^{-2} \mathrm{~s}^{-1}\right)$.

expressing in Arabidopsis roots and is transported into nuclei upon irradiation of roots with UV-B. Over-expression of UVR8 greatly reduces root growth under light exposure and aggravates their weaker performance under the osmotic stress (Fasano et al., 2014). In comparison to the control plants, the primary root and lateral root densities were 13 and $60 \%$, respectively. This indicates that auxin-dependent lateral root growth was most hampered. Indeed the root-phenotypes of the $35 S$ - UVR 8 plants are reminiscent that one of auxin mutant (Zhao, 2010). The analysis of lateral roots showed that the number of lateral root primordia and emerged lateral roots of the 35S-UVR8 plants was 12 and 68\%, respectively, reduced in comparison to the control plants (Fasano et al., 2014). Flavonoids accumulation was found to be 2.2-fold increased in the root of the UVR8-over-expressing plants, whereas the content of IAA-conjugates showed a tendency to decrease (Fasano et al., 2014). Thus, the defects in cell expansion of the $35 S-U V R 8$ roots could be associated to the increased levels of flavonoids which, in turn, alter polar auxin transport and/or auxin homeostasis (e.g., Santelia et al., 2008).

Flavonoids are synthesized in roots, regulating root branching, gravitropism, and stress adaptation (Brown et al., 2001; Buer and Muday, 2004; Agati et al., 2011; Emiliani et al., 2013). Flavonoid concentrations are significantly higher in combined stress-treated plants than in those treated with UV-B alone (Hughes et al., 2010; Comont et al., 2012). Together, all these reports suggest that UVR8, via the control of flavonoid accumulation, might be a common intermediate in light and hormone signaling pathways to regulate root growth and development under abiotic stress challenges. Besides UV-B, drought and salinity have also been associated with anthocyanin accumulations in various tissues including roots (Agati et al., 2011; Emiliani et al., 2013; Meng, 2014). Importantly in this respect, the light-induced stimulation of Arabidopsis root growth is mediated via the COP1-mediated accumulation of anthocyanins (Meng, 2014).

\section{IMPACT OF LIGHT ON SALINITY AVOIDANCE VIA ROOT HALOTROPISM}

Although root apices growing in soil are known to be at a front line that can be exposed to salt stress, an impact of light on modulation of the sensitivity of roots to salinity has not been considered to date. Importantly, most experiments using the laboratory grown Arabidopsis seedlings are using roots exposed to light, although root apices outside in the nature are mostly in darkness.

As shown in the Figure 3, we have demonstrated that light exposure affects the root response to the salinity stress. Columbia WT seedlings were grown on agar plates containing $\mathrm{NaCl}$ only at their bottom parts. With this system, root tropism responses to salinity, halotropism, can be observed. Our methods followed the protocol described in (Galvan-Ampudia et al., 2013; Rosquete and Kleine-Vehn, 2013). After replacing bottom part of agar with the $\mathrm{NaCl}$-agar, plastic dishes were covered with aluminum foil to allow dark treatment. Light/dark period was $16 \mathrm{~h} / 8 \mathrm{~h}$ and light intensity was about the $120 \mu \mathrm{mol} \mathrm{m} \mathrm{m}^{-2} \mathrm{~s}^{-1}$, comparable to conditions in Galvan-Ampudia et al. (2013). Both the darkand light-grown roots grew straight to the boundary of two agar media in control experiments with $0 \mathrm{mM} \mathrm{NaCl}$ (Figure 3). On the other hand, roots growing in darkness have higher sensitivity to $\mathrm{NaCl}$ than that roots exposed to light (Table 1). Dark-grown roots showed halotropism by avoiding salt-enriched agar areas at all concentrations of $\mathrm{NaCl}$ (Figure 3; Table 1). At the $100 \mathrm{mM}$ concentration of $\mathrm{NaCl}$, light-grown roots kept growing into the salty part of agar across the borderline between two agar parts even after several days. This suggests that light either prevents roots to accomplish the halotropism or that light lowers the sensitivity of Arabidopsis roots to perceive a gradient of salinity. The fact that light grown roots performed halotropism at higher concentrations of $\mathrm{NaCl}$ (Table 1) suggests that light interferes with the elusive root's ability to sense the $\mathrm{Na}^{+}$gradients (Maathuis, 2014). As root apices of roots growing outside in the nature are typically located deep in the soil in darkness, it can be expected that their halotropism is more efficient than for roots of laboratory grown seedlings.

\section{LIGHT-INDUCED ROOT GROWTH IS EXPENSIVE AND ALTERS PHYSIOLOGY AND MORPHOLOGY OF WHOLE SEEDLINGS}

It is important to be aware that light-induced stimulation of root growth is changing the physiology of whole seedlings/plants. Figure 4 summarizes light-induced root growth mediated via COP1 interactions with the actin cytoskeleton (Dyachok et al., 2011) and anthocyanin biosynthesis (Meng, 2014). Both SCAR and PAP mediated pathways require sucrose as energy source (Kurata and Yamamoto, 1997; Kircher and Schopfer, 2012; Maier et al., 2013; Meng, 2014). Roots lacking ANGUSTIFOLIA3 (AN3) transcription coactivator have reduced anthocyanin levels and longer roots in light than WT roots (Meng, 2014). In contrast, the an 3 mutant roots are shorter that WT roots when grown in darkness. Interestingly, AN3 binds to COP1 promoter to inhibit the light-induced root elongation (Meng, 2014). Besides anthocyanins, light-exposed roots show also rather dramatic increase of 


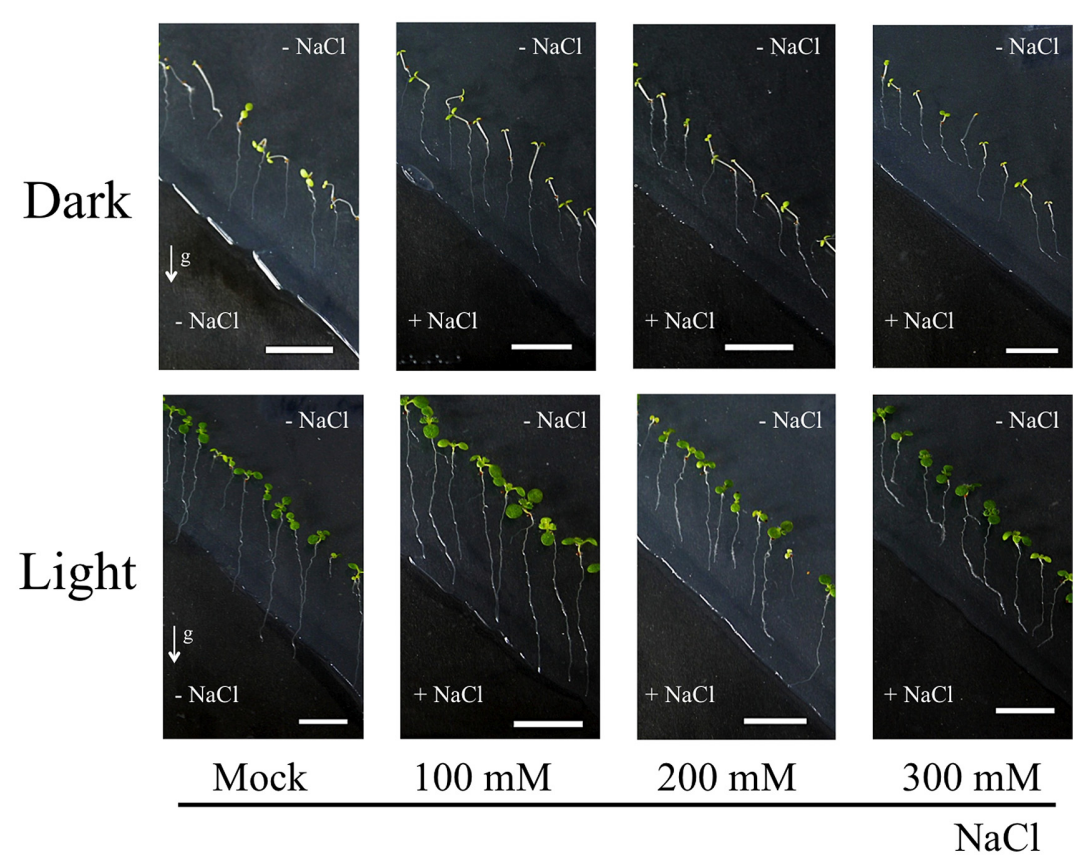

FIGURE 3 | Light environment affects sensitivity of Arabidopsis roots to salinity. Seedlings of Col-0 were firstly grown on $1 / 2 \mathrm{MS}$ media for 5 days. Bottom part of agar was removed diagonally and new $1 / 2 \mathrm{MS}$ media containing $\mathrm{NaCl}$ was added. Petri dishes were placed either in light or dark condition for 3 days. Roots growing on agar plates in dark/light conditions with $0,100,200$, and $300 \mathrm{mM} \mathrm{NaCl}$ media in the bottom half of Petri dishes. The method used for imposing the root halotropism is following exactly the protocol as published by Galvan-Ampudia etal. (2013). White arrows indicate the gravity vector. All seedlings were grown in vertical position. Bar indicates $1 \mathrm{~cm}$.
Table 1 | Halotropic bendings of Arabidopsis roots grown in different light conditions.

\begin{tabular}{lllll}
\hline & Mock & $\mathbf{1 0 0} \mathbf{~ m M}$ & $\mathbf{2 0 0} \mathbf{~ m M}$ & $\mathbf{3 0 0} \mathbf{~ m M}$ \\
\hline Dark & $0 \%(n=25)$ & $26 \%(n=23)$ & $90 \%(n=30)$ & $92.3 \%(n=26)$ \\
Light & $0 \%(n=29)$ & $18.5 \%(n=27)$ & $16.7 \%(n=30)$ & $46.4 \%(n=28)$
\end{tabular}

Roots have been considered halotropic when scored root apex angles are greater than $45^{\circ}$ with respect of the gravity vector (= same angle with the boundary of agar).

phenylpropanoid metabolism, inducing not only flavonoids but also monolignol glucosides (Hemm et al., 2004). Possible impacts of light on the Casparian bands formation in endodermis can be expected and easily tested.

Light-induced actin polymerization, auxin polar transport, root growth and anthocyanin biosynthesis are energetically demanding processes. The increased demand of sucrose for the root photomorphogenesis (Costigan et al., 2011; Warnasooriya and Montgomery, 2011; Yokawa etal., 2013) is going at the expense of other potential sinks of the plant body (Kurata and Yamamoto, 1997; Yazdanbakhsh et al., 2011; Kircher and Schopfer, 2012). Moreover, salt stress perceived locally at the root apex is rapidly spread throughout the plant body via systemic signaling (Choi etal., 2014; Gilroy etal., 2014). Therefore, it is important to be aware that illumination of roots has rather dramatic consequences for the whole seedling's physiology and morphology.

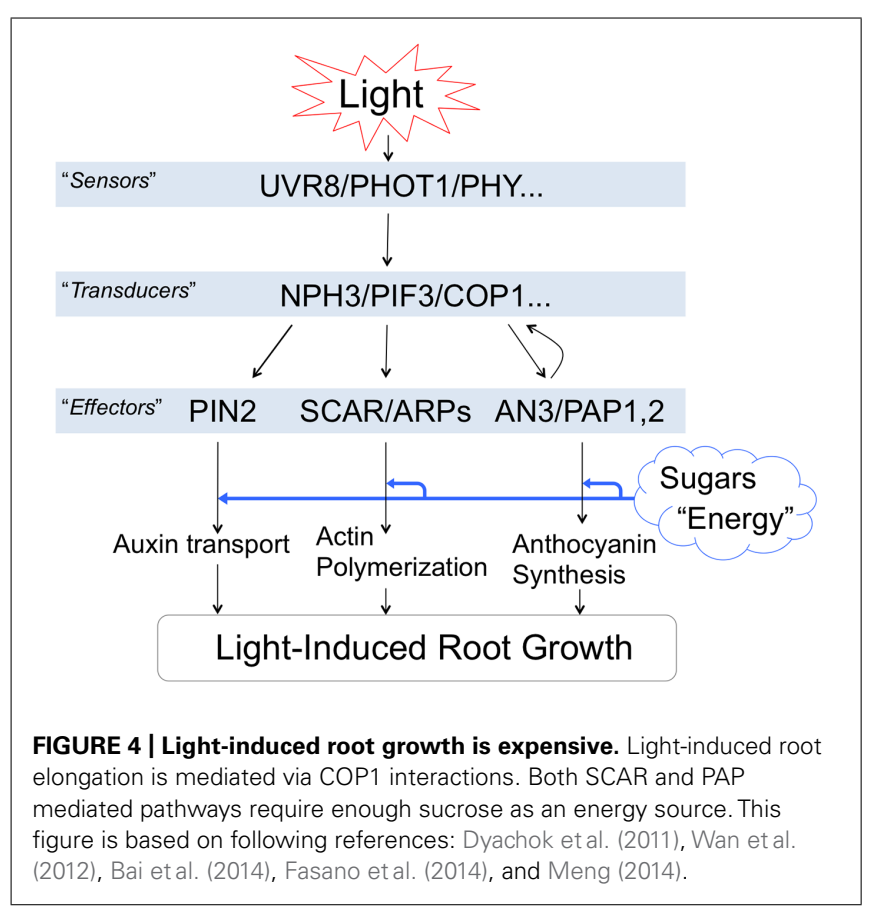

\section{CONCLUSIONS AND PERSPECTIVES}

Our results using salt stress reveal that light exposed roots show different behavior and responses under salt stress. One possible scenario, based on reports that illuminated roots enhance 
Table 2 | Arabidopsis root lengths in different salt and light conditions.

\begin{tabular}{lllll}
\hline & Mock & $\mathbf{1 0 0} \mathbf{~ m M}$ & $\mathbf{2 0 0} \mathbf{~ m M}$ & $\mathbf{3 0 0} \mathbf{~ m M}$ \\
\hline Dark & $10.2 \pm 2.9 \mathrm{~mm}$ & $11.6 \pm 2.6 \mathrm{~mm}$ & $9.3 \pm 1.8 \mathrm{~mm}$ & $10.4 \pm 2.4 \mathrm{~mm}$ \\
Light & $21.1 \pm 4.4 \mathrm{~mm}$ & $20.5 \pm 2.7 \mathrm{~mm}$ & $15.9 \pm 2.9 \mathrm{~mm}$ & $14.5 \pm 3.1 \mathrm{~mm}$ \\
\hline
\end{tabular}

Root lengths were measured after 3-days-incubation on $\mathrm{NaCl}$ treatment plates. 20-30 roots in each plate were measured and standard deviations are presented next to the average length $(\mathrm{mm})$.

strigolactone levels (Koltai et al., 2011) and strigolactone increases drought and salt tolerance of roots (Ha et al., 2014), is that the light-exposed roots are less sensitive to salt stress. Whereas the dark-grown roots show halotropism (salt avoidance tropism) by growing around the salt-enriched agar parts, the light-exposed roots grow into the salt-enriched agar if $\mathrm{NaCl}$ levels are not too high (Tables 1 and 2). As light-induced strigolactone levels modify also root responses to low phosphate (Mayzlish-Gati et al., 2012), one can propose that exposure of Arabidopsis roots to light is modifying their whole physiology. In fact, our preliminary data reveal that Arabidopsis roots exposed to light show changes the sensitivity also to the aluminum toxicity (Kagenishi et al., in preparation). In addition, IAA levels in light exposed $(1 \mathrm{~h})$ maize roots were more than doubled compared to control levels (Yokawa et al., in preparation). It is intriguing that enhanced strigolactone levels resemble light-induced effects on roots. It was shown that light impacts on the actin cytoskeleton, also increased abundance and recycling of PIN2 auxin transporter (Laxmi et al., 2008; Dyachok et al., 2011; Wan et al., 2012; Pandya-Kumar et al., 2014). Moreover, salt stress, drought stress, cold stress, alkaline stress, aluminum toxicity; all these challenges target the PIN2 auxin transporter which is expressed in the root apex transition zone (discussed in Baluška et al., 2010; Baluška and Mancuso, 2013). In order to avoid light exposure of roots, we recommend using of the partially darkened Petri dishes (Yokawa et al., 2011, 2013; Xu et al., 2013). This is important as stressing roots with light is modifying not only root responses to diverse stresses but also the overall physiology of such seedlings. For example, it has been reported that circadian rhythms in Arabidopsis roots are governed by the shoot part (James et al., 2008). Importantly in this respect, ROS signaling and homeostasis was shown to be a major modulator of circadian rhythms both in prokaryotes and eukaryotes (Edgar et al., 2012; Lai et al., 2012; Stangherlin and Reddy, 2013). It is possible that seedlings will change even their circadian clock when roots are illuminated.

Although plant roots are heterotrophic plant organs, they require active suppression of photosynthetic gene expression. Tyrosylprotein sulfotransferase (TPST) protein HPS7 emerged recently as crucial player controlling this active suppression (Kang etal., 2014). Interestingly enough, hsp7 mutant roots show enhanced photosynthesis-related effects under phosphate deficiency stress. Previous studies identified Golden-Like transcription factors GLK1 and GLK2 involved in activation of photosynthetic genes in roots (Waters et al., 2009; Kobayashi et al., 2013). Both $h s p 7$ and GLK-ox mutant roots do not show stunted root growth and any other phenotypes when grown in darkness (Kang et al., 2014).
Finally, the plant physiology perspective of the light-induced root growth in Arabidopsis is considering the high root growth rate as a sign of optimal root growth conditions. In stark contrast, the plant neurobiology interpretation of this increased root growth rate is that the light-exposed roots are experiencing stress and that such stressed roots are trying to escape from this unfavorable situation (Yokawa et al., 2011, 2013; Xu et al., 2013). Alpi et al. (2007), critics of the plant neurobiology initiative claimed that '.. plant neurobiology does not add to our understanding of plant physiology, plant cell biology or signaling.' Now, some 7 years later, it is getting obvious that plants and their roots are behaviorally much more complex than envisioned in the framework of classical plant physiology (Trewavas, 2005, 2009, 2014; Trewavas and Baluška, 2011; Baluška and Mancuso, 2013; Pierik and Testerink, 2014). Illumination of the roots is common laboratory praxis ever since Arabidopsis thaliana was introduced as model organism to plant sciences. However, it is important to be aware that light exposure of roots emerges as stress factor for the laboratory grown Arabidopsis seedlings. This is clear example for the usefulness of viewing plants as actively living and sensitive organisms solving their own plant-specific problems in intelligent manner.

\section{ACKNOWLEDGMENTS}

Ken Yokawa was supported by the JSPS (Japanese Society for the Promotion of Science) Postdoctoral Fellowship. We thank Prof. Gareth I. Jenkins (University of Glasgow) for providing us with seeds of the UVR8::GFP line.

\section{REFERENCES}

Agati, G., Biricolti, S., Guidi, L., Ferrini, F., Fini, A., and Tattini, M. (2011). The biosynthesis of flavonoids is enhanced similarly by UV radiation and root zone salinity in L. vulgare leaves. J. Plant Physiol. 168, 204-212. doi: 10.1016/j.jplph.2010.07.016

Akiyama, K., Matsuzaki, K., and Hayashi, H. (2005). Plant sesquiterpenes induce hyphal branching in arbuscular mycorrhizal fungi. Nature 435, 824-827. doi: 10.1038/nature03608

Alpi, A., Amrhein, N., Bertl, A., Blatt, M. R., Blumwald, E., Cervone, F., et al. (2007). Plant neurobiology: no brain, no gain? Trends Plant Sci. 12, 135-136. doi: 10.1016/j.tplants.2007.03.002

Ang, L. H., Chattopadhyay, S., Wei, N., Oyama, T., Okada, K., Batschauer, A., et al. (1998). Molecular interaction between COP1 and HY5 defines a regulatory switch for light control of Arabidopsis development. Mol. Cell 1, 213-222. doi: 10.1016/S1097-2765(00)80022-2

Aroca, R., Ruiz-Lozano, J. M., Zamarreño, A. M., Paz, J. A., García-Mina, J. M., Pozo, M. J., et al. (2013). Arbuscular mycorrhizal symbiosis influences strigolactone production under salinity and alleviates salt stress in lettuce plants. J. Plant Physiol. 170, 47-55. doi: 10.1016/j.jplph.2012.08.020

Bai, S., Yao, T., Li, M., Guo, X., Zhang, Y., Zhu, S., et al. (2014). PIF3 is involved in the primary root growth inhibition of Arabidopsis induced by nitric oxide in the light. Mol. Plant 7, 616-625. doi: 10.1093/mp/sst142

Baluška, F., and Mancuso, S. (2013). Root apex transition zone as oscillatory zone. Front. Plant Sci. 4:354. doi: 10.3389/fpls.2013.00354

Baluška, F., Mancuso, S., Volkmann, D., and Barlow, P. W. (2004). Root apices as plant command centres: the unique 'brain-like' status of the root apex transition zone. Biologia 59, 9-17.

Baluška, F., Mancuso, S., Volkmann, D., and Barlow, P. W. (2010). Root apex transition zone: a signalling - response nexus in the root. Trends Plant Sci. 15, 402-408. doi: 10.1016/j.tplants.2010.04.007

Baluška, F., Volkmann, D., and Barlow, P. W. (1996). Specialized zones of development in roots: view from the cellular level. Plant Physiol. $112,3-4$. 
Baluška, F., Volkmann, D., and Menzel, D. (2005). Plant synapses: actin-based domains for cell-to-cell communication. Trends Plant Sci. 10, 106-111. doi: 10.1016/j.tplants.2005.01.002

Bartels, D., and Sunkar, R. (2005). Drought and salt tolerance in plants. Crit. Rev. Plant Sci. 24, 23-58. doi: 10.1080/07352680590910410

Briggs, W. R. (2014). Phototropism: some history, some puzzles, and a look ahead. Plant Physiol. 164, 13-23. doi: 10.1104/pp.113.230573

Briggs, W., and Lin, C. T. (2012). Photomorphogenesis - from one photoreceptor to 14: 40 years of progress. Mol. Plant 3, 531-532. doi: 10.1093/mp/sss059

Brown, B. A., Cloix, C., Jiang, G. H., Kaiserli, E., Herzyk, P., Kliebenstein, D. J., et al. (2005). A UV-B-specific signaling component orchestrates plant UV protection. Proc. Natl. Acad. Sci. U.S.A. 102, 18225-18230. doi: 10.1073/pnas.0507187102

Brown, D. E., Rashotte, A. M., Murphy, A. S., Normanly, J., Tague, B. W., Peer, W. A., et al. (2001). Flavonoids act as negative regulators of auxin transport in vivo in Arabidopsis. Plant Physiol. 126, 524-535. doi: 10.1104/pp.126.2.524

Bu, Q., Lv, T., Shen, H., Luong, P., Wang, J., Wang, Z., et al. (2014). Regulation of drought tolerance by the F-box protein MAX2 in Arabidopsis. Plant Physiol. 164, 424-439. doi: 10.1104/pp.113.226837

Buer, C. S., and Muday, G. K. (2004). The transparent testa4 mutation prevents flavonoid synthesis and alters auxin transport and the response of Arabidopsis roots to gravity and light. Plant Cell 16, 1191-1205. doi: 10.1105/tpc.020313

Burbach, C., Markus, K., Zhang, Y., Schlicht, M., and Baluška, F. (2012). Photophobic behavior of maize roots. Plant Signal. Behav. 7, 874-878. doi: $10.4161 /$ psb. 21012

Bussell, J. S., Gwynn-Jones, D., Griffith, G. W., and Scullion, J. (2012). Aboveand below-ground responses of Calamagrostis purpurea to UV-B radiation and elevated $\mathrm{CO}_{2}$ under phosphorus limitation. Physiol. Plant. 145, 619-628. doi: 10.1111/j.1399-3054.2012.01595.x

Choi, W. G., Toyota, M., Kim, S. H., Hilleary, R., and Gilroy, S. (2014). Salt stress-induced $\mathrm{Ca}^{2+}$ waves are associated with rapid, long-distance root-toshoot signaling in plants. Proc. Natl. Acad. Sci. U.S.A. 111, 6497-6502. doi: 10.1073/pnas.1319955111

Cluis, C. P., Mouchel, C. F., and Hardtke, C. S. (2004). The Arabidopsis transcription factor HY5 integrates light and hormone signaling pathways. Plant J. 38, 332-347. doi: 10.1111/j.1365-313X.2004.02052.x

Comont, D., Winters, A., and Gwynn-Jones, D. (2012). Acclimation and interaction between drought and elevated UV-B in A. thaliana: differences in response over treatment, recovery and reproduction. Ecol. Evol. 2, 2695-2709. doi: $10.1002 /$ ece 3.387

Costigan, S. E., Warnasooriya, S. N., Humphries, B. A., and Montgomery, B. L. (2011). Root-localized phytochrome chromophore synthesis is required for photoregulation of root elongation and impacts root sensitivity to jasmonic acid in Arabidopsis. Plant Physiol. 157, 1138-1150. doi: 10.1104/pp.111. 184689

Darwin, C. R. (1880). The Power of Movements in Plants. London: John Murray.

Darwin, F. (1879). Über das negativ wachstum heliotropischer wurzeln im licht und im finstern. Arb. D. Bot. Inst. Würzburg 2, 521-528.

Datta, S., Hettiarachchi, C., Johansson, H., and Holm, M. (2007). SALT TOLERANCE HOMOLOG2, a B-box protein in Arabidopsis that activates transcription and positively regulates light-mediated development. Plant Cell 19, 3242-3255. doi: 10.1105/tpc.107.054791

Datta, S., Hettiarachchi, G. H., Deng, X. W., and Holm, M. (2006). Arabidopsis CONSTANS-LIKE3 is a positive regulator of red light signaling and root growth. Plant Cell 18, 70-84. doi: 10.1105/tpc.105.038182

Dyachok, J., Zhu, L., Liao, F., He, J., Huq, E., and Blancaflor, E. B. (2011). SCAR mediates light-induced root elongation in Arabidopsis through photoreceptors and proteasomes. Plant Cell 23, 3610-3626. doi: 10.1105/tpc.111. 088823

Edgar, R. S., Green, E. W., Zhao, Y., van Ooijen, G., Olmedo, M., Qin, X., et al. (2012). Peroxiredoxins are conserved markers of circadian rhythms. Nature 485, 459-464. doi: 10.1038/nature11088

Emiliani, J., Grotewold, E., Falcone Ferreyra, M. L., and Casati, P. (2013). Flavonols protect Arabidopsis plants against UV-B deleterious effects. Mol. Plant 6, 1376 1379. doi: $10.1093 / \mathrm{mp} / \mathrm{sst} 021$

Fasano, R., Gonzalez, N., Tosco, A., Piaz, F. D., Docimo, T., Serrano, R., et al. (2014). Role of Arabidopsis-UV RESISTANCE LOCUS 8 in plant growth reduction under osmotic stress and low levels of UV-B. Mol. Plant 5, 773-791. doi: $10.1093 / \mathrm{mp} / \mathrm{ssu} 002$
Favory, J. J., Stec, A., Gruber, H., Rizzini, L., Oravecz, A., Funk, M., et al. (2009). Interaction of COP1 and UVR8 regulates UV-B-induced photomorphogenesis and stress acclimation in Arabidopsis. EMBO J. 28, 591-601. doi: 10.1038/emboj.2009.4

Flematti, G. R., Ghisalberti, E. L., Dixon, K. W., and Trengove, R. D. (2004). A compound from smoke that promotes seed germination. Science 305:977. doi: $10.1126 /$ science. 1099944

Fukai, S., and Cooper, M. (1995). Development of drought-resistant cultivars using physio-morphological traits in rice. Field Crops Res. 40, 67-86. doi: 10.1016/03784290(94)00096-U

Galvan-Ampudia, C. S., Julkowska, M. M., Darwish, E., Gandullo, J., Korver, R. A., Brunoud, G., et al. (2013). Halotropism is a response of plant roots to avoid a saline environment. Curr. Biol. 23, 2044-2050. doi: 10.1016/j.cub.2013. 08.042

Gilroy, S., Suzuki, N., Miller, G., Choi, W. G., Toyota, M., Devireddy, A. R., et al. (2014). A tidal wave of signals: calcium and ROS at the forefront of rapid systemic signaling. Trends Plant Sci. 19, 623-630. doi: 10.1016/j.tplants.2014.06.013

Guo, Y., Zheng, Z., La Clair, J. J., Chory, J., and Noel, J. P. (2013). Smoke-derived karrikin perception by the $\alpha / \beta$-hydrolase KAI 2 from Arabidopsis. Proc. Natl. Acad. Sci. U.S.A. 110, 8284-8289. doi: 10.1073/pnas.1306265110

Ha, C. V., Leyva-González, M. A., Osakabe, Y., Tran, U. T., Nishiyama, R., Watanabe, Y., etal. (2014). Positive regulatory role of strigolactone in plant responses to drought and salt stress. Proc. Natl. Acad. Sci. U.S.A. 111, 851-856. doi: 10.1073/pnas.1322135111

Hayward, A., Stirnberg, P., Beveridge, C., and Leyser, O. (2009). Interactions between auxin and strigolactone in shoot branching control. Plant Physiol. 151, 400-412. doi: 10.1104/pp.109.137646

Hemm, M. R., Rider, S. D., Ogas, J., Murry, D. J., and Chapple, C. (2004). Light induces phenylpropanoid metabolism in Arabidopsis roots. Plant J. 38, 765-778. doi: 10.1111/j.1365-313X.2004.02089.x

Hughes, N. M., Reinhardt, K., Feild, T. S., Gerardi, A. R., and Smith, W. K. (2010). Association between winter anthocyanin production and drought stress in angiosperm evergreen species. J. Exp. Bot. 61, 1699-1709. doi: 10.1093/jxb/erq042

James, A. B., Monreal, J. A., Nimmo, G. A., Kelly, C. L., Herzyk, P., Jenkins, G. I., et al. (2008). The circadian clock in Arabidopsis roots is a simplified slave version of the clock in shoots. Science 322, 1832-1835. doi: 10.1126/science.1161403

Jeong, J., and Choi, G. (2013). Phytochrome-interacting factors have both shared and distinct biological roles. Mol. Cells 35, 371-380. doi: 10.1007/s10059-0130135-5

Kang, J., Yu, H., Tian, C., Zhou, W., Li, C., Jiao, Y., et al. (2014). Suppression of photosynthetic gene expression in roots is required for sustained root growth under phosphate deficiency. Plant Physiol. 165, 1156-1170. doi: 10.1104/pp.114.238725

Kim, B. C., Tennessen, D. J., and Last, R. L. (1998). UV-B-induced photomorphogenesis in Arabidopsis thaliana. Plant J. 15, 667-674. doi: 10.1046/j.1365313x.1998.00246.x

Kircher, S., and Schopfer, P. (2012). Photosynthetic sucrose acts as cotyledon-derived long-distance signal to control root growth during early seedling development in Arabidopsis. Proc. Natl. Acad. Sci. U.S.A. 109, 11217-11221. doi: 10.1073/pnas.1203746109

Kliebenstein, D. J., Lim, J. E., Landry, L. G., and Last, R. L. (2002). Arabidopsis UVR8 regulates ultraviolet- $\mathrm{B}$ signal transduction and tolerance and contains sequence similarity to human regulator of chromatin condensation. Plant Physiol. 130, 234-243. doi: 10.1104/pp.005041

Kobayashi, K., Sasaki, D., Noguchi, K., Fujinuma, D., Komatsu, H., Kobayashi, M., et al. (2013). Photosynthesis of root chloroplasts developed in Arabidopsis lines overexpressing GOLDEN2-LIKE transcription factors. Plant Cell Physiol. 54, 1365-1377. doi: 10.1093/pcp/pct086

Koltai, H. (2011). Strigolactones are regulators of root development. New Phytol. 190, 545-549. doi: 10.1111/j.1469-8137.2011.03678.x

Koltai, H., Cohen, M., Chesin, O., Mayzlish-Gati, E., Bécard, G., Puech, V., et al. (2011). Light is a positive regulator of strigolactone levels in tomato roots. J. Plant Physiol. 168, 1993-1996. doi: 10.1016/j.jplph.2011.05.022

Koshiba, T., Yamauchi, K., Matsuyama, H., Miyakado, M., Sori, I., and Satô, M. (1993). Flavin-photosensitized production of indole-3-acetaldehyde from tryptophan. Tetrahedron Lett. 34, 7603-7606. doi: 10.1016/S0040-4039(00)60411-2

Kurata, T., and Yamamoto, K. T. (1997). Light stimulated root elongation in Arabidopsis thaliana. J. Plant Physiol. 151, 346-351. doi: 10.1016/S01761617(97)80263-5 
Lai, A. G., Doherty, C. J., Mueller-Roeber, B., Kay, S. A., Schippers, J. H., and Dijkwel, P. P. (2012). CIRCADIAN CLOCK-ASSOCIATED 1 regulates ROS homeostasis and oxidative stress responses. Proc. Natl. Acad. Sci. U.S.A. 109, 17129-17134. doi: 10.1073/pnas.1209148109

Laxmi, A., Pan, J., Morsy, M., and Chen, R. (2008). Light plays an essential role in intracellular distribution of auxin efflux carrier PIN2 in Arabidopsis thaliana. PLoS ONE 3:e1510. doi: 10.1371/journal.pone.0001510

Li, G., and Xue, H. W. (2007). Arabidopsis PLDzeta2 regulates vesicle trafficking and is required for auxin response. Plant Cell 19, 281-295. doi: $10.1105 /$ tpc. 106.041426

Li, X., and Zhang, W. (2008). Salt-avoidance tropism in Arabidopsis thaliana. Plant Signal. Behav. 3, 351-353. doi: 10.4161/psb.3.5.5371

Liao, H., Rubio, G., Yan, X., Cao, A., Brown, K. M., and Lynch, J. P. (2001). Effect of phosphorus availability on basal root shallowness in common bean. Plant Soil 232, 69-79. doi: 10.1023/A:1010381919003

Liu, J., Rowe, J., and Lindsey, K. (2014). Hormonal crosstalk for root development: a combined experimental and modeling perspective. Front. Plant Sci. 5:116. doi: $10.3389 /$ fpls.2014.00116

López-Ráez, J. A., Kohlen, W., Charnikhova, T., Mulder, P., Undas, A. K., Sergeant, M. J., et al. (2010). Does abscisic acid affect strigolactone biosynthesis? New Phytol. 187, 343-354. doi: 10.1111/j.1469-8137.2010.03291.x

Maathuis, F. J. (2014). Sodium in plants: perception, signalling, and regulation of sodium fluxes. J. Exp. Bot. 65, 849-858. doi: 10.1093/jxb/ert326

Maier, A., Schrader, A., Kokkelink, L., Falke, C., Welter, B., Iniesto, E., et al. (2013). Light and the E3 ubiquitin ligase COP1/SPA control the protein stability of the MYB transcription factors PAP1 and PAP2 involved in anthocyanin accumulation in Arabidopsis. Plant J. 74, 638-651. doi: 10.1111/tpj.12153

Mancuso, S., Marras, A. M., Mugnai, S., Schlicht, M., Zársky, V., Li, G., et al. (2007). Phospholipase dzeta2 drives vesicular secretion of auxin for its polar cell-cell transport in the transition zone of the root apex. Plant Signal. Behav. 2, 240-244. doi: 10.4161/psb.2.4.4566

Mayzlish-Gati, E., De-Cuyper, C., Goormachtig, S., Beeckman, T., Vuylsteke, M., Brewer, P. B., etal. (2012). Strigolactones are involved in root response to low phosphate conditions in Arabidopsis. Plant Physiol. 160, 1329-1341. doi: 10.1104/pp.112.202358

Meng, L. S. (2014). Transcription coactivator Arabidopsis ANGUSTIFOLIA3 modulates anthocyanin accumulation and light-induced root elongation through transrepression of constitutive photomorphogenic 1. Plant Cell Environ. doi: 10.1111/pce.12456 [Epub ahead of print].

Nelson, D. C., Flematti, G. R., Riseborough, J. A., Ghisalberti, E. L., Dixon, K. W., and Smith, S. M. (2010). Karrikins enhance light responses during germination and seedling development in Arabidopsis thaliana. Proc. Natl. Acad. Sci. U.S.A. 107, 7095-7100. doi: 10.1073/pnas.0911635107

Nick, P., Han, M. J., and An, G. (2009). Auxin stimulates its own transport by shaping actin filaments. Plant Physiol. 151, 155-167. doi: 10.1104/pp.109.140111

Oyama, T., Shimura, Y., and Okada, K. (1997). The Arabidopsis HY5 gene encodes a bZIP protein that regulates stimulus-induced development, of root and hypocotyl. Genes Dev. 11, 2983-2995. doi: 10.1101/gad.11.22.2983

Pandya-Kumar, N., Shema, R., Kumar, M., Mayzlish-Gati, E., Levy, D., Zemach, H., et al. (2014). Strigolactone analog GR24 triggers changes in PIN2 polarity, vesicle trafficking and actin filament architecture. New Phytol. 202, 1184-1196. doi: $10.1111 /$ nph.12744

Pardo, J. M. (2010). Biotechnology of water and salinity stress tolerance. Curr. Opin. Biotechnol. 21, 185-196. doi: 10.1016/j.copbio.2010.02.005

Pierik, R., and Testerink, C. (2014). The art of being fexible: how to escape from shade, salt, and drought. Plant Physiol. 166, 5-22. doi: 10.1104/pp.114.239160

Raghavendra, A. S., Gonugunta, V. K., Christmann, A., and Grill, E. (2010). ABA perception and signalling. Trends Plant Sci. 15, 395-401. doi: 10.1016/j.tplants.2010.04.006

Rizzini, L., Favory, J. J., Cloix, C., Faggionato, D., O’Hara, A., Kaiserli, E., et al. (2011). Perception of UV-B by the Arabidopsis UVR8 protein. Science 332, 103-106. doi: $10.1126 /$ science. 1200660

Rosquete, M. R., and Kleine-Vehn, V. (2013). Halotropism: turning down the salty date. Curr. Biol. 23, R927-R929. doi: 10.1016/j.cub.2013.08.020

Santelia, D., Henrichs, S., Vincenzetti, V., Sauer, M., Bigler, L., Klein, M., et al. (2008). Flavonoids redirect PIN-mediated polar auxin fluxes during root gravitropic responses. J. Biol. Chem. 283, 31218-31226. doi: 10.1074/jbc. M710122200
Sassi, M., Lu, Y., Zhang, Y., Wang, J., Dhonukshe, P., Blilou, I., et al. (2012). COP1 mediates the coordination of root and shoot growth by light through modulation of PIN1 and PIN2-dependent auxin transport in Arabidopsis. Development 139, 3402-3412. doi: 10.1242/dev.078212

Sharp, R. E., Poroyko, V., Hejlek, L. G., Spollen, W. G., Springer, G. K., Bohnert, H. J., et al. (2004). Root growth maintenance during water deficits: physiology to functional genomics. J. Exp. Bot. 55, 2343-2351. doi: 10.1093/jxb/erh276

Shen, H., Luong, P., and Huq, E. (2007). The F-box protein MAX2 functions as a positive regulator of photomorphogenesis in Arabidopsis. Plant Physiol. 145, 1471-1483. doi: 10.1104/pp.107.107227

Shen, H., Zhu, L., Bu, Q. Y., and Huq, E. (2012). MAX2 affects multiple hormones to promote photomorphogenesis. Mol. Plant 5, 750-762. doi: 10.1093/mp/ sss 029

Sibout, R., Sukumar, P., Hettiarachchi, C., Holm, M., Muday, G. K., and Hardtke, C. S. (2006). Opposite root growth phenotypes of hy 5 versus hy 5 hyh mutants correlate with increased constitutive auxin signaling. PLoS Genet. 2:e202. doi: 10.1371/journal.pgen.0020202

Stangherlin, A., and Reddy, A. B. (2013). Regulation of circadian clocks by redox homeostasis. J. Biol. Chem. 288, 26505-26511. doi: 10.1074/jbc.R113.457564

Stirnberg, P., Furner, I. J., and Leyser, H. M. O. (2007). MAX2 participates in an SCF complex which acts locally at the node to suppress shoot branching. Plant J. 50, 80-94. doi: 10.1111/j.1365-313X.2007.03032.x

Sun, F., Zhang, W., Hu, H., Li, B., Wang, Y., Zhao, Y., et al. (2008). Salt modulates gravity signaling pathway to regulate growth direction of primary roots in Arabidopsis. Plant Physiol. 146, 178-188. doi: 10.1104/pp.107.109413

Sun, X. D., and Ni, M. (2011). HYPOSENSITIVE TO LIGHT, an alpha/beta fold protein, acts downstream of ELONGATED HYPOCOTYL 5 to regulate seedling de-etiolation. Mol. Plant 4, 116-126. doi: 10.1093/mp/ssq055

Taniguchi, Y. Y., Taniguchi, M., Tsuge, T., Oka, A., and Aoyama, T. (2010). Involvement of Arabidopsis thaliana phospholipase Dzeta2 in root hydrotropism through the suppression of root gravitropism. Planta 231, 491-497. doi: 10.1007/s00425-009-1052-x

Toh, S., McCourt, P., and Tsuchiya, Y. (2012). HY5 is involved in strigolactonedependent seed germination in Arabidopsis. Plant Signal. Behav. 7, 556-558. doi: 10.4161/psb.19839

Tong, H., Leasure, C. D., Hou, X., Yuen, G., Briggs, W., and He, Z.-H. (2008). Role of root UV-B sensing in Arabidopsis early seedling development. Proc. Natl. Acad. Sci. U.S.A. 105, 21039-21044. doi: 10.1073/pnas.0809942106

Trewavas, A. (2005). Plant intelligence. Naturwissenschaften 92, 401-413. doi: $10.1007 / \mathrm{s} 00114-005-0014-9$

Trewavas, A. (2009). What is plant behaviour? Plant Cell Environ. 32, 606-616. doi: 10.1111/j.1365-3040.2009.01929.x

Trewavas, A. (2014). Plant Behaviour and Intelligence. Oxford: Oxford University Press. doi: 10.1093/acprof:oso/9780199539543.001.0001

Trewavas, A., and Baluška, F. (2011). The ubiquity of consciousness. The ubiquity of consciousness, cognition and intelligence in life. EMBO Rep. 12, 1221-1225. doi: 10.1038/embor.2011.218

Tsuchiya, Y., Vidaurre, D., Toh, S., Hanada, A., Nambara, E., Kamiya, Y., etal. (2010). A small-molecule screen identifies new functions for the plant hormone strigolactone. Nat. Chem. Biol. 6, 741-749. doi: 10.1038/ nchembio. 435

Umehara, M., Hanada, A., Yoshida, S., Akiyama, K., Arite, T., Takeda-Kamiya, N., et al. (2008). Inhibition of shoot branching by new terpenoid plant hormones. Nature 455, 195-200. doi: 10.1038/nature07272

Waller, F., and Nick, P. (1997). Response of actin microfilaments during phytochrome-controlled growth of maize seedlings. Protoplasma 200, 154-162. doi: 10.1007/BF01283291

Wan, Y., Jasik, J., Wang, L., Hao, H., Volkmann, D., Menzel, D., et al. (2012). The signal transducer NPH3 integrates the phototropin1 photosensor with PIN2based polar auxin transport in Arabidopsis root phototropism. Plant Cell 24, 551-565. doi: 10.1105/tpc.111.094284

Warnasooriya, S. N., and Montgomery, B. L. (2011). Spatial-specific regulation of root development by phytochromes in Arabidopsis thaliana. Plant Signal. Behav. 6, 2047-2050. doi: 10.4161/psb.6.12.18267

Waters, M. T., Nelson, D. C., Scaffidi, A., Flematti, G. R., Sun, Y. K., Dixon, K. W., et al. (2012). Specialisation within the DWARF14 protein family confers distinct responses to karrikins and strigolactones in Arabidopsis. Development 139, 12851295. doi: $10.1242 /$ dev. 074567 
Waters, M. T., Wang, P., Korkaric, M., Capper, R. G., Saunders, N. J., and Langdale, J. A. (2009). GLK transcription factors coordinate expression of the photosynthetic apparatus in Arabidopsis. Plant Cell 21, 1109-1128. doi: 10.1105/tpc.108. 065250

Werner, T., Nehnevajova, E., Köllmer, I., Novák, O., Strnad, M., Krämer, U., etal. (2010). Root-specific reduction of cytokinin causes enhanced root growth, drought tolerance, and leaf mineral enrichment in Arabidopsis and tobacco. Plant Cell 22, 3905-3920. doi: 10.1105/tpc.109. 072694

Woolley, J. T., and Stoller, E. W. (1978). Light penetration and light-induced seed germination in soil. Plant Physiol. 61, 597-600. doi: 10.1104/pp.61.4.597

Xu, W., Ding, G., Yokawa, K., Baluška, F., Li, Q. F., Liu, Y., et al. (2013). An improved agar-plate method for studying root growth and response of Arabidopsis thaliana. Sci. Rep. 3:1273. doi: 10.1038/srep01273

Yazdanbakhsh, N., Sulpice, R., Graf, A., Stitt, M., and Fisahn, J. (2011). Circadian control of root elongation and $\mathrm{C}$ partitioning in Arabidopsis thaliana. Plant Cell Environ. 34, 877-894. doi: 10.1111/j.1365-3040.2011. 02286.x

Yokawa, K., and Baluška, F. (2014). Pectins, ROS homeostasis and UV-B responses in plant roots. Phytochemistry doi: 10.1016/j.phytochem.2014.08.016 [Epub ahead of print].

Yokawa, K., Kagenishi, T., and Baluška, F. (2013). Root photomorphogenesis in laboratory-maintained Arabidopsis seedlings. Trends Plant Sci. 18, 117-119. doi: 10.1016/j.tplants.2013.01.002

Yokawa, K., Kagenishi, T., Kawano, T., Mancuso, S., and Baluška, F. (2011). Illumination of Arabidopsis roots induces immediate burst of ROS production. Plant Signal. Behav. 6, 1460-1464. doi: 10.4161/psb.6.10.18165
Yokawa, K., Koshiba, T., and Baluška, F. (2014). Light-dependent control of redox balance and auxin biosynthesis in plants. Plant Signal. Behav. 9:e29522. doi: $10.4161 /$ psb. 29522

Yoneyama, K., Yoneyama, K., Takeuchi, Y., and Sekimoto, H. (2007). Phosphorus deficiency in red clover promotes exudation of orobanchol, the signal for mycorrhizal symbionts and germination stimulant for root parasites. Planta 225, 1031-1038. doi: 10.1007/s00425-006-0410-1

Zhao, Y. (2010). Auxin biosynthesis and its role in plant development. Annu. Rev. Plant Biol. 61, 49-64. doi: 10.1146/annurev-arplant-042809-112308

Conflict of Interest Statement: The authors declare that the research was conducted in the absence of any commercial or financial relationships that could be construed as a potential conflict of interest.

Received: 27 October 2014; accepted: 28 November 2014; published online: 12 December 2014.

Citation: Yokawa K, Fasano R, Kagenishi T and Baluška F (2014) Light as stress factor to plant roots - case of root halotropism. Front. Plant Sci. 5:718. doi: 10.3389/fpls. 2014.00718

This article was submitted to Plant Physiology, a section of the journal Frontiers in Plant Science.

Copyright (c) 2014 Yokawa, Fasano, Kagenishi and Baluška. This is an open-access article distributed under the terms of the Creative Commons Attribution License (CC BY). The use, distribution or reproduction in other forums is permitted, provided the original author(s) orlicensor are credited and that the original publication in this journal is cited, in accordance with accepted academic practice. No use, distribution or reproduction is permitted which does not comply with these terms. 